\title{
Correlations Between Deaf-Muteness and Cephalometric Characteristics in Adults
}

\author{
Aurel-Claudiu Vartolomei \\ Suciu Ilinca Elena \\ Ursache Elena Mihaela, MD \\ University of Medicine and Pharmacy of Tirgu-Mures, \\ Faculty of Dentistry, Romania
}

Doi: 10.19044/esj.2017.v13n30p1 URL:http://dx.doi.org/10.19044/esj.2017.v13n30p1

\begin{abstract}
Objective: The purpose of this study was to assess any existing correlations between the phonatory function obviously affected in deaf-mute patients and dento-maxillary and/or facial anomalies. Material and Methods: The study comprised 55 deaf-mute patients (28 males and 27 females) aged between 23 and 76 from 2 cities of Romania, belonging to the Hearing Deficiency Persons' Association. 13 were edentulous. Each patient was clinically and radiographically assessed. We applied computer assisted interpretetation of the profile teleradiographies using AudaxCeph and Scanora Lite 3.2.6 software for the following parameters: SNA, SNB, ANB, SN/ML, FH/ML, NL/ML, NL/+1 and ML/-1 angles, Ls-ELine, Li-ELine, UP and LP distances. The data was compared to normal values as referred to in the mentioned computer programs by using Student's t-tests and the Bland Altman plot. Results: The following characteristics were identified as being statistically different from the normal values: SN/ML with a mean of $-5,5^{\circ}$, FH/ML by $6,2^{\circ}$, NL/ML with $-5,2^{\circ}$, Ls-ELine by $-4,2 \mathrm{~mm}$ and Li-ELine with a mean of $-3,7 \mathrm{~mm}$. Conclusions: Deaf-mute patients tend to present hypodivergent vertical skeletal patterns, anterior mandibular growth/rotation and skeletal deep bite and also protruded lips, aspects which must be taken into consideration when commencing an orthodontic treatment.
\end{abstract}

Keywords: Deaf-muteness, measurements, teleradiography, dento-maxillary anomalies

\section{Introduction}

Worldwidely, deafness affects about 1.1 billion people to a certain degree. By 2004, 124.2 million people (out of which 107.9 came from lowand medium-income contries) presented moderate to severe disability. From 
these, 65 millions had gained the impairment during childhood. At birth, 3 out of 1000 people in developed countries and 6 out of 1000 people in developing countries have hearing impariment. The prevalence of deafness increases with age. For the age group of 20 to 35, the rate of hearing loss is $3 \%$, for the group of 44 to 55 it is $11 \%$ and for those aged between 65 and 85 the rate is $45 \%$. Naturally, the inability to hear denies the ability to speak.

It is beyond the purpose of this article to discuss the physiology of the phonation, the formation and emitting of vocals and consonants but it is of use to debate the influence of the phonation upon the development of the dento-maxillary system.

During speech, a series of modifications concerning the mandible's position, the caliber of the pharynx, the tonus, the shape and the position of the tongue take place, with variable contacts with the palate and the dental arches. The muscular activity during this function objectifies through various forces applied on the dental arches and maxillary bones. Cauhépé and co. have demonstrated that the exerted muscular forces are relatively important, although they are intermittent. In the case of a physiological phonatory function, a developing action is expressed upon the development of soft and hard structures. This also includes the air column.

In normal articulary behaviours, the following can be emphasized:

-the recline of the tongue against the lingual surface of the inferior incisors; -the interposition of the tongue towards the premolars;

-the interposition of the tongue towards the incisors;

-the recline of the tongue against the palatal surface of the upper incisors;

The deficiencies in speech articulation indicate a failure of the speaker in obtaining a typification and a normal fixation of the control upon the effectors (tongue, palate, lips) wich move in the structural frame of the oral cavity. These deficiencies manifest themselves by repeating, missing out, distortioning sounds, drawling, babbling and irregular syllabling.

There is also a tight correlation between deglutition and phonation disorders and Bouvet considers that only reeducation of both functions can lead to healing. If phonatory disorders tend to influence the development of the dentoalveolar arches, then thrust disorders, if present, have a similar tendency.

Research upon the relationship between dentomaxillary anomalies and disturbance of phonatory function have led to the following conclusions: 1. Speaking disorders can be present although the development of the dento-maxillary apparatus is stable.

2. Dento-maxillary anomalies can be present in persons with normally acoustic speech.

3. Dento-maxillary anomalies become a direct cause of speaking defects only if the deformities are so pronounced that the tongue, lips or soft palate 
can no longer adapt (Jenkins says $80 \%$ of blabbers have dento-maxillary anomalies).

4. Speaking issues and dento-maxillary anomalies can have mutual origins, both determined by abnormal muscular behaviours with complex functional imbalances. (Boboc, 2003).

There are three types of hearing loss: sensorineural hearing loss, conductive hearing loss and mixed hearing loss. The degrees of hearing loss are: very mild (16-25 dB), mild (26-40 dB), moderate (41-55 dB), moderate to severe $(56-70 \mathrm{~dB}$ ), severe $(71-90 \mathrm{~dB}$ ), profound (more than $90 \mathrm{~dB}$ ) and total. The causes of hearing loss are genetic (50\%), perinatal, postnatal and unknown.

The aims of this study were to:

1. Assess any existing correlations between the phonatory function obviously affected in deaf-mute patients and dento-maxillary anomalies;

2. Assess the lips' and tongue's position in this type of patients.

\section{Methodology}

The profile teleradiography is nowadays the most utilized means of investigation when diagnosing dento-maxillary anomalies, describing skeletal morphology and growth patterns, treatment planning and results evaluation.

The study targeted a number of 100 deaf-mute subjects aged between 23 and 76 with an average of 42 .

They were totally or severe deaf from childhood and belonged to the Hearing Deficiency Persons' Associations in Brasov and Tirgu Mures cities from Romania. Through the agency of a specialized translator each and every subject was explained the purpose and the methods of the study and the ones who consented to it, meaning 55 (28 males and 27 females), were accepted.

Fig. 1. Sex * Dental Status Crosstabulation

\begin{tabular}{|c|c|c|c|c|c|}
\hline \multicolumn{3}{|r|}{$p-0.65$} & \multicolumn{2}{|c|}{ Dental Status } & \multirow[t]{2}{*}{ Total } \\
\hline & & & $\mathrm{D}$ & ET & \\
\hline \multirow{7}{*}{ Sex } & \multirow{3}{*}{$\mathrm{F}$} & Count & 22 & 6 & 28 \\
\hline & & $\%$ within Sex & $78,6 \%$ & $21,4 \%$ & $100,0 \%$ \\
\hline & & $\%$ within Dental Status & $52,4 \%$ & $46,2 \%$ & $50,9 \%$ \\
\hline & \multirow{4}{*}{ M } & Count & 20 & 7 & 27 \\
\hline & & $\%$ within Sex & $74,1 \%$ & $25,9 \%$ & $100,0 \%$ \\
\hline & & $\%$ within Dental Status & $47,6 \%$ & $53,8 \%$ & $49,1 \%$ \\
\hline & & Count & 42 & 13 & 55 \\
\hline \multirow[t]{2}{*}{ Total } & & $\%$ within Sex & $76,4 \%$ & $23,6 \%$ & $100,0 \%$ \\
\hline & & $\%$ within Dental Status & $100,0 \%$ & $100,0 \%$ & $100,0 \%$ \\
\hline
\end{tabular}


Each patient was clinically and radiographically assessed. We applied computer assisted interpretation of the profile teleradiographies using AudaxCeph (McLaughlin analysis) and Scanora Lite 3.2.6 software. The following skeletal parameters were assessed: SNA, SNB, ANB, SN/ML, FH/ML, NL/ML, NL/+1 and ML/-1 angles.

We noticed that in addition to the sign language used, the subjects thoroughly articulate certain sounds when communicating, trying to issue words. Thus, we assessed the Ls-ELine, Li-ELine, UP and LP distances to observe any tongue or soft tissue position modifications.

Following the examinations, we observed that 13 of the subjects were edentulous and their findings were not taken into consideration as craniofacial modifications describing this physiopathological condition would interfere with the final results.

The data was further compared to normal values as refered to in the mentioned computer programs by using Student's t-tests and the Bland Altman plot.



Fig. 2. Profile teleradiography analysis of 24 year old deaf-mute patient

Skeletal parameters utilized are defined as follows:

The SNA angle $\left(80-84^{\circ}\right)$ indicates the anteroposterior position of the upper maxilla to the cranial base (maxillary prognathism/retrognathism). 
The SNB angle $\left(78-82^{\circ}\right)$ indicates the anteroposterior position of the mandible to the cranial base (mandibular prognathism/retrognathism).

The ANB angle $\left(2^{\circ}\right)$ indicates the relative relation between the upper maxillary and the mandible to the cranial base (class I/II/III).

The SN/ML angle $\left(33-35^{\circ}\right)$ indicates the inclination of the mandible to the cranial base (increased facial height-posterior growth pattern/decreased facial height-anterior growth).

The FH/ML angle $\left(26^{\circ}\right)$ indicates the vertical skeletal pattern (hypo/hyperdivergent pattern).

The NL/ML angle $\left(28^{\circ}\right)$ indicates the inclination of the mandible to the upper maxillary (skeletal open-/deepbite).

Dentoalveolar parameters:

The NL/+1 angle $\left(110^{\circ}\right)$ indicates the inclination of the upper incisors to their skeletal base (incisor protrusion/retrusion).

The ML/-1 angle $\left(95^{\circ}\right)$ indicates the position of the anterior part of the mandibular arch to its skeletal base (incisor protrusion/retrusion).

Soft tissue/aesthetics' parameters:

The Ls-Eline parameter $(-4 \mathrm{~mm})$ indicates the normal position, the protrusion or the retrusion of the upper lip.

The Li-ELine parameter $(-2 \mathrm{~mm})$ indicates the normal position, the protrusion or the retrusion of the lower lip. The aesthetic ELine is defined as the tangent line to the chin and the most anterior part of the most protruding lip.

The Upper Pharynx/UP line $(17.5 \mathrm{~mm})$ is the shortest distance between the anterior part of the soft palate and the posterior wall of the pharynx.

The Lower Pharynx/LP line (11-14 mm, McNamara, 1984) is the distance between the base of the tongue and the posterior wall of the pharynx measured on the mandibular plane.

These two measurements indicate the position of the tongue.



Fig. 3. Upper and Lower Pharynx distances - uncommonly used measurements 


\section{Results}

Concerning the following skeletal and dentoalveolar parameters: SNA, SNB, ANB, ML/+1 and NL/-1 angles, the measurements found are similar to the normal values, with insignificant statistical differences. The Bland Altman plot compares the differences between the obtained values and the normal values.

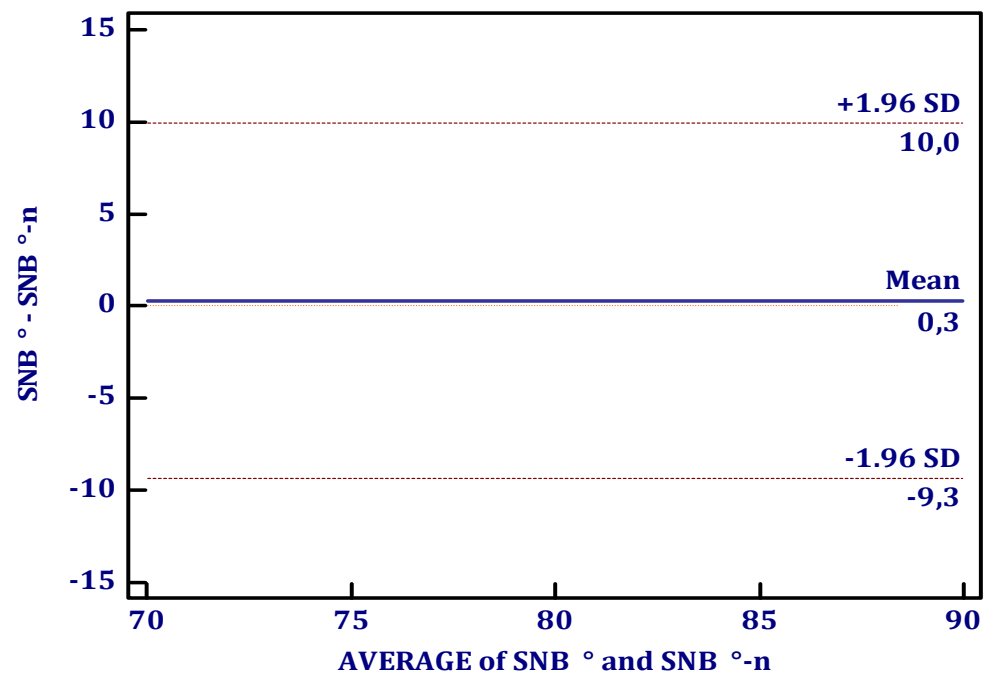

Fig. 4. Example of Bland Altman plot applied for the SNB angle: the average of differences is 0.3 and the measurement agreement domain between the differences runs from -9.3 to 12.9. The values obtained outside this interval are aberrant.

Regarding the SN/ML, FH/ML and NL/ML angles we obtained statistically important differences as follows:

The obtained average value for the SN/ML angle is lower by a mean of $-5.5^{\circ}$ than the given value.

The average measurement obtained for the $\mathrm{FH} / \mathrm{ML}$ angle is smaller by a mean of $-6.2^{\circ}$ than the normal value.

Also, the obtained average value for the NL/ML angle is lower by a mean of $-5.2^{\circ}$ compared to the normal value. 


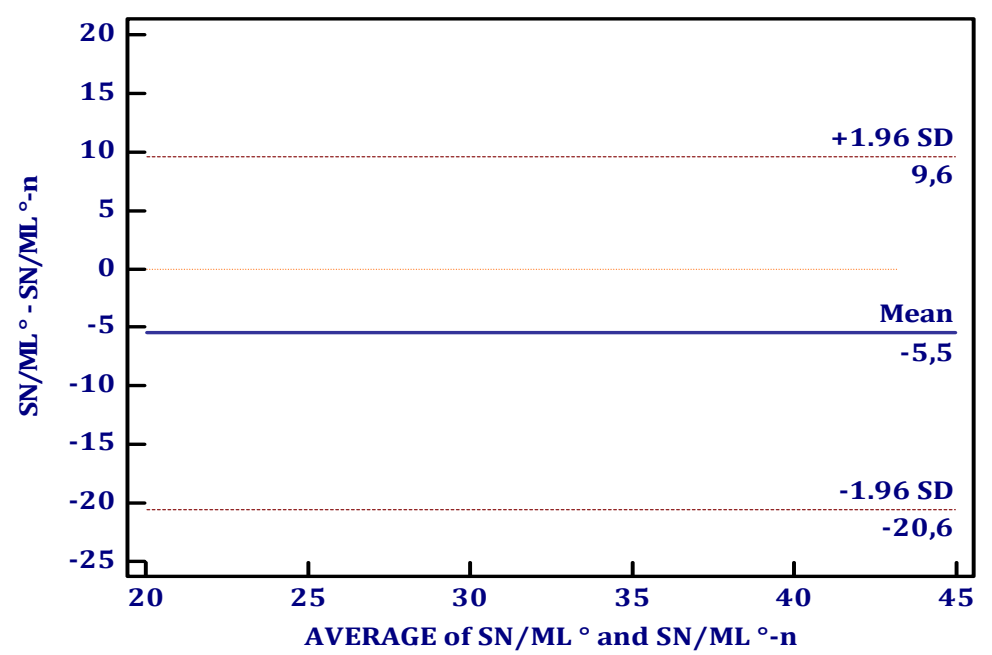

Fig. 5. Example of Bland Altman method applied for the SN/ML angle showing the average of differences of $-5.5^{\circ}$

Next, the UP and LP distances are not statistically different than the normal values. We additionally compared the position of the tongue in edentulous with dentulous patients and found no statistically relevant differences.

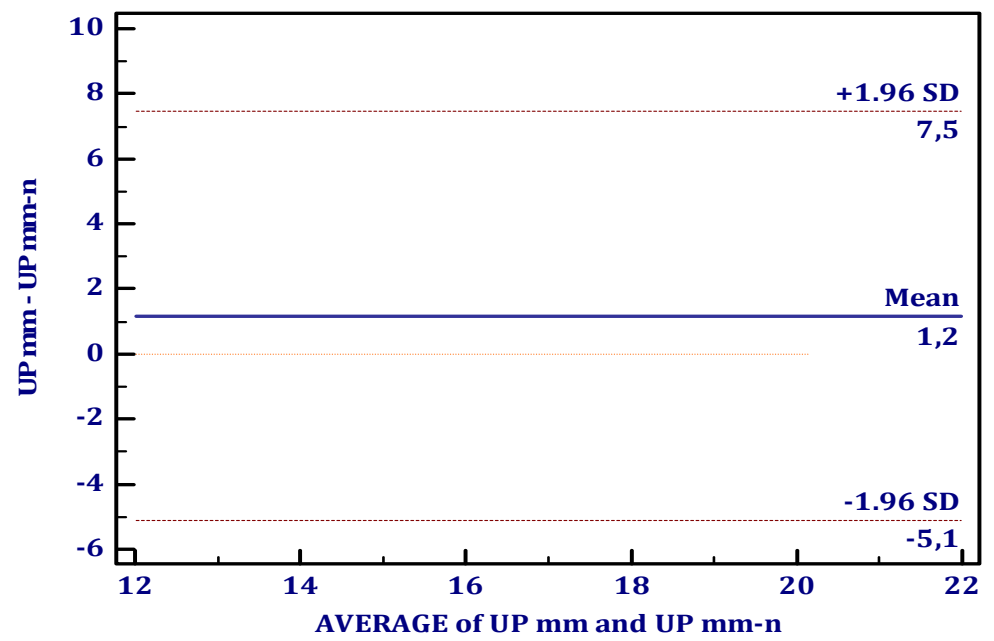

Fig. 6. Bland Altman plot for Upper Pharynx line with a low statistical difference of $1.2 \mathrm{~mm}$ 


\begin{tabular}{|c|c|c|c|c|c|c|}
\hline \multirow{2}{*}{} & $\begin{array}{c}\text { Dental } \\
\text { Status }\end{array}$ & $\mathrm{N}$ & Mean & $\begin{array}{c}\text { Std. } \\
\text { Deviation }\end{array}$ & $\begin{array}{c}\text { Normal } \\
\text { value }\end{array}$ & P value \\
\hline \multirow{2}{*}{ UP mm } & $\mathrm{E}$ & 13 & 16,952 & 3,3139 & 17,4 & \multirow{2}{*}{0.78} \\
\cline { 2 - 6 } & $\mathrm{D}$ & 42 & 17,240 & 3,2161 & 17,4 & \\
\hline \multirow{2}{*}{ LP mm } & $\mathrm{E}$ & 13 & 11,908 & 5,0095 & 12,5 & \multirow{2}{*}{0.61} \\
\cline { 2 - 6 } & $\mathrm{D}$ & 42 & 11,144 & 2,9050 & 12,5 & \\
\hline \multirow{2}{*}{ Age } & $\mathrm{E}$ & 13 & 66,23 & 6,508 & & \\
\cline { 2 - 6 } & $\mathrm{D}$ & 42 & 42,50 & 14,35 & & \\
\hline
\end{tabular}

Fig. 8. Comparison of Upper and Lower Pharynx values in dentulous and edentulous patients

On the contrary, the Ls-ELine and Li-ELine values are different than the given values by a mean of by $-4,2 \mathrm{~mm}$ and $-3,7 \mathrm{~mm}$.

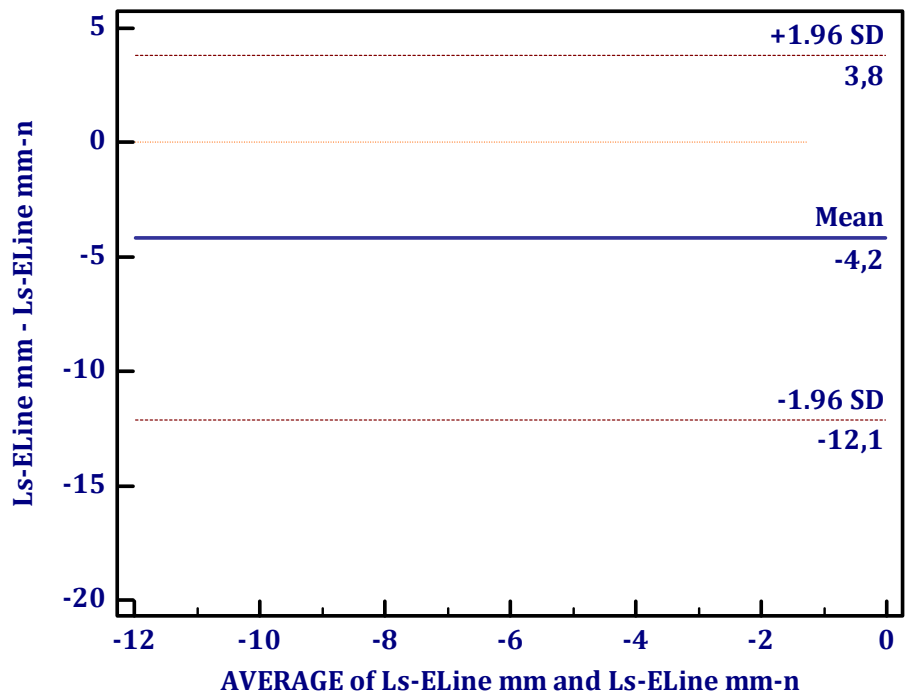

Fig. 7. Bland Altman method applied to Ls-ELine parameter, $-4.2 \mathrm{~mm}$ differences average

\section{Discussions}

We could not identify similar studies in literature and the possible explanations for this might be:

- the difficulty in finding such patients and constituting a numerous lot; - the difficulty of collaborating with them. The slight deviations in values can be influenced by the defective communication between the deaf-mute subject and the radiologist while performing the X-Ray and proper positioning in the cephalostat. For example cephalometric measurements are erroneous if the patient swallows and the soft palate takes an inverted $\mathrm{V}$ shape following the contraction of the tensor and levator veli palatini muscles. Moreover, the position of the tongue is influenced. 
- orthodontic treatment is normally conducted in young patients although the bounderies have stretched to adult age very much. The advanced age of the patients included in this study is thus not to be neglected.

It is possible that the skeletal and facial modifications not be related to deaf-muteness itself but to a whole range of different factors which usually cause dento-maxillary anomalies.

Although the subjects do not utilize their tongue in normal speech, the organ actively participates in the articulation of certain sound and this can lead to hyperactivity or hypertonicity. Thus, the position is normal and there were no differences between the two lots of dentulous and edentulous patients.

A statistical evaluation would be more clinching on groups of death-mute subjects categorized by the type of dento-maxillary anomaly and compared with normal subjects of the same anomaly and age.

\section{Conclusion}

The deaf-mute subjects in our study do not present a specific skeletal, dental and facial morphology.

1. There are statistically significant differences concerning only the vertical skeletal parameters and not the sagittal. The upper maxilla and the mandible are accurately positioned to the cranial base. Thus, the three angles (SN/ML ${ }^{\circ}, \mathrm{FH} / \mathrm{ML}^{\circ}$ and $\mathrm{NL} / \mathrm{ML}^{\circ}$ ) present modifications as follows: deceased facial height, hypodivergence and deepbite, all interconnected.

2. There are as well statistically important differences concerning the soft tissue/aesthetic measurements Ls-ELine and Li-ELine in the same direction of decrease. Thus, both lips tend to be retruded. This is in contradiction with the previous findigs, as hypodivergent patients normally present with protruded lips but again can represent the accommodation of soft tissues.

3. The position of the tongue in these patients is normal.

4. These aspects must be taken into consideration during correct treatment planning in orthodontic patients despite the fact that it is a rather infrequent and less advantaged category.

\section{References:}

1. Global Burden of Disease Study 2013, Collaborators (22 August 2015). "Global, regional, and national incidence, prevalence, and years lived with disability for 301 acute and chronic diseases and injuries in 188 countries, 1990-2013: a systematic analysis for the Global Burden of Disease Study 2013.". Lancet. 386 (9995): 743800. 
2. Deafness and hearing loss Fact sheet $\mathrm{N}^{\circ} 300 "$. March 2015 WHO (2008). The global burden of disease: 2004 update (PDF). Geneva, Switzerland: World Health Organization. p. 35

3. Olusanya, BO; Neumann, KJ; Saunders, JE (1 May 2014). "The global burden of disabling hearing impairment: a call to action.". Bulletin of the World Health Organization. 92 (5): 367-73

4. Florica Glăvan, Marcel Moise, Cristina D. Bratu, Ortodonție și Ortopediedento-facială, Editura Eubeea, 2008, 92;

5. Gheorghe Boboc, Aparatul Dento-Maxilar, Editura Medicală București, 2003, 370:386;

6. Lasak, JM; Allen, P; McVay, T; Lewis, D (Mar 2014). "Hearing loss diagnosis and management.". Primary care 41 (1): 19-31

7. Elzouki Abdelaziz Y. Textbook of clinical pediatrics Sensory Disorders, Feldman, Heidi M. (2 ed.). Berlin: Springer; 2012, p. 602.

8. Smith, RJH; Shearer, AE; Hildebrand, MS; Van Camp, G; Pagon, RA; Adam, MP; Ardinger, HH; Wallace, SE; Amemiya, A; Bean, LJH; Bird, TD; Fong, CT; Mefford, HC; Smith, RJH; Stephens, K (2014). "Deafness and Hereditary Hearing Loss Overview 